\title{
Mermaid health - identifying health issues related to mermaiding
}

\author{
Matthieu J. Guitton ${ }^{1,2}$ \\ ${ }^{1}$ Faculty of Medicine, Laval University, Quebec City, QC, Canada \\ ${ }^{2}$ Institut Universitaire en Santé Mentale de Québec, Quebec City, QC, Canada
}

\begin{abstract}
Background: Mermaiding - swimming with a leg-covering monofin mimicking the tail of a mermaid - is an emerging aquatic activity, which has gained a marked popularity over the last few years. However, no study so far has documented the potential health issues or risks of injuries related to this practice.

Materials and methods: This study surveyed professional mermaids cumulating an estimated total of 19,147 h of in-water mermaiding, regarding their health issues and injuries. While mermaiding bears some risks, the occurrence of problematic conditions appears limited. Interestingly, the profile of health issues experienced by professional mermaids is unique and specific, and clearly different from both professional swimmers and surfers. Results: Self-reported health issues related to mermaiding could be divided into issues specifically related to mermaiding activities (ear issues, reported by $87.5 \%$ of the respondents; sea life encounters, $50 \%$; cold-related issues, $37.5 \%$; compromised access to air, 25\%), issues related to the tail and fins (back pain, 50\%; lower limbs issues, 37.5\%), and issues related to water quality (eye issues, 25\%; waterborne diseases, 12.5\%). Clear differences appear between professional and recreational mermaiding activities. Conclusions: The results presented here will help to build safer conditions for mermaiding activities and to develop adapted responses from health specialists to help this unique yet growing population of aquatic performers and athletes.
\end{abstract}

(Int Marit Health 2017; 68, 1: 12-18)

Key words: aquatic athletes, ear infection, mermaiding, monofin, preventive medicine, waterborne diseases, waterborne illnesses

\section{INTRODUCTION}

Mermaiding - the activity of swimming with a leg-covering monofin mimicking the tail of a mermaid - is an emerging form of swimming, which has gained a marked popularity over the last few years [1, 2]. Supported by an important media coverage [1, 3, 4], this new swimming form is becoming more and more widespread, with "mermaid schools" opening across the world since 2012, notably in the Philippines, Australia, Germany, Canada, or the United States of America [1, 5].

Due to the novelty of the discipline, there is currently a lack of documentation regarding the potential health-related risks that could arise from this practice, as well as the threats one could encounter during the exercise. With the multiplication of settings and practitioners, some swimming facilities have decided to ban altogether mermaiding in the hope to avoid any future issue. For instance, the city council of Edmonton (Alberta, Canada) took the decision to forbid mermaiding in public swimming pools in May 2015 [1]. Obviously, such decisions are mostly motivated by perceived potential threats rather than by evidence-based data. However, in the absence of convincing data, criticizing such decisions from officials aiming at protecting the public is problematic.

While the current public interest for mermaiding as a recreational activity is relatively new, mermaiding itself has been present in the entertainment world since some times. Indeed, professional mermaids and other relatively similar forms of aquatic entertainers have been practicing since more than a decade [2]. Numerous places across the world, including hotels, casino or amusement parks include 
mermaids swimming in various types of tanks or other aquatic entertainers in their entertainment programmes. Taking into account the experience of these professional mermaids is likely to represent a powerful way to identify and evaluate which are the potential health issues and risks of injury that may be associated with mermaiding. Based on a self-reported survey strategy, this study is the first one to document health issues related to mermaiding, and provides valuable insights which should allow us to increase the safety of this unique vocation.

\section{MATERIALS AND METHODS PARTICIPANTS}

Professional mermaids were identified through their websites and presence on social networks. Participants were initially contacted via email which explained the overall objectives of the study. Once gathered, all data were treated anonymously.

\section{SEMI-STRUCTURED INTERVIEWS}

Mermaiding can take place in a large variety of settings and not all of them are suitable for direct scientific observation. Therefore, data collection was based on self-reports of participants' experience, a strategy which has been demonstrated to be a valid approach in order to document occurrence of illnesses, injuries, and health issues in the context of multi-site aquatic activities [6]. Participants were asked to answer a semi-structured interview documenting three domains: their professional practice, the occurrence of chronic health issues related to mermaiding, and the occurrence of accidents or injuries related to mermaiding. The survey could be answered either by filling a questionnaire offline, or through a Skype interview.

The following information were gathered in order to document the respondents' professional practice as mermaids: age, gender, date since practicing as a professional mermaid, the number of hours per week performing as a professional mermaid or aquatic entertainer, an estimation of the total number spent as a professional mermaid, the countries visited as a professional mermaid, and the settings in which their professional mermaid activities were taking place (in percentage of the time spent as a mermaid for the settings). For the settings, an initial list of eight categories was proposed, including: hotels, resorts, casinos, nightclubs, private parties, mermaid schools, open water, other (specify). For the categories hotels, resorts, casino, nightclubs, and private parties, it was indicated that this was referring to settings with water tank or other water installation. Other categories which were mentioned by the respondents included aquariums, (underwater) movies/films, water sports events, and "dry activities" (acting as a mermaid outside of water). In addition, participants had to report whether they had any swimming, diving, or related formation or certificates, and any first aid/para-medic formation or certificates.

Respondents had then to self-report mermaiding-related health issues, by describing any health issue or injury experienced since practicing mermaiding at a professional level. The following categories were suggested, based on what is documented in the current literature regarding swimmers' and aquatic athletes' health issues and injuries [7]: upper limbs, back and spine, lower limbs, respiratory pathways, ear, others. Respondents were then asked to report any accident which led to injuries (even minor) they encountered as professional mermaid. For each accident, the following information were asked: (a) where did the accident took place (setting, country), (b) description of the context (what happened), (c) description of the injury, (d) did someone helped the respondent, (e) did the helper had any first aid training, (f) what would have helped then, or how the situation could have been avoided. Respondents were asked to describe any potentially dangerous situation they might have encountered, following a similar response pattern (a) where it happened (setting, country), (b) what happened, (c) what was the threat perceived, (d) did someone helped the respondent, (e) did this helper had any first aid training, (f) how this situation could have been avoided. Finally, space was provided to add any comment that the respondents would have wanted to share. This survey structure allowed generating an important corpus which could be further analysed, and limited the risk of missing critical information by multiplying the categories of questions.

\section{DATA ANALYSES}

Data related to health aspects were extracted from the different parts of the survey and categorised accordingly to the type of issues and the anatomical localisation. Data regarding the degree of severity of each type of issue or injury were also extracted from the verbatim. In case of doubt, the respondents were contacted again for clarification. For each respondent, if the total number of hours spent as a professional mermaid was not indicated, estimation was made as a function of the self-reported numbers of hours per week and of the total duration since the beginning of the respondent activities as a professional mermaid. An estimated cumulated total of the number of hours was generated to characterise the overall experience gathered by the respondents. Estimation of the total number of hours spent in pool water and salt water were computed as follow: sum of the number of hours in the categories hotels, resorts, casinos, nightclubs, private parties, mermaid schools, movies/films, water sports events for the total number of hours spent in pool water; and sum of the number of hours in the categories open water and aquariums for the total number of hours spent in salt water. When applicable, results were presented as mean \pm standard deviation (SD). 


\section{RESULTS \\ PROFESSIONAL PRACTICE}

Data from 8 professional mermaids were gathered. All respondents were women, $33.1 \pm 6.7$ years old (median: 31 , max: 43 , min: 26 ), practicing mermaiding professionally since $5.5 \pm 3.7$ year (starting dates between 2003 and 2015). The respondents of this study performed as professional mermaids in $5.5 \pm 4.1$ different countries per respondent for a total of 31 different countries (listed in Table 1).

The respondents were practicing mermaiding in professional settings $10.2 \pm 10.3 \mathrm{~h}$ per week, generating an estimated total of 19,780 cumulated hours of active mermaiding experience (Table 2). From them, 96.8\% represented "wet" (in-water) activities, accounting for 19,147 h. Two third of these wet activities were taking place in pools (66\%, accounting for an estimated total of $12,639 \mathrm{~h}$ ) and

Table 1. Countries in which mermaiding activities surveyed in this study took place

$\begin{array}{lll}\text { Australia } & \text { Indonesia } & \text { Portugal } \\ \text { Azerbaijan } & \text { Jamaica } & \text { Singapore } \\ \text { The Bahamas } & \text { Japan } & \text { Spain } \\ \text { Canada } & \text { Malaysia } & \text { Switzerland } \\ \text { Chile } & \text { Maldives } & \text { Thailand } \\ \text { Egypt } & \text { Mauritius } & \text { Tonga } \\ \text { Fiji } & \text { Mexico } & \text { United Kingdom } \\ \text { France } & \text { Monaco } & \text { United States } \\ \text { Germany } & \text { Morocco } & \text { of America } \\ \text { Greece } & \text { The Netherlands } & \text { Uruguay } \\ \text { Grenada } & \text { Philippines } & \end{array}$

one third in salt water (34\%, accounting for an estimated total of 6,508 h). All of the respondents had some degree of professional diving formation (either in free diving or scuba diving). All but 1 (87.5\%) respondent had some level of first aid formal training.

\section{SELF-REPORTED HEALTH ISSUES RELATED TO MERMAIDING}

Health issues related to mermaiding were identified through the analysis of the answers of the respondents, covering chronic health issues, acute problems, and dangerous situations encountered in the course of their mermaiding practice (Table 3). Since the focus of the present study was on mermaiding as an aquatic activity, problems which happened when performing outside of the water were excluded. Globally, self-reported health issues related to mermaiding can be divided into the following categories: ear issues, back pain, cold-related issues, sea life encounters, lower limbs issues, eye issues, compromised access to air, and other infections. Of note, while obviously all the health issues mentioned here by mermaids are related to in-water activity and are not necessary typical for mermaiding, what is typical for mermaiding is their degree of occurrence.

Ear issues were clearly the most prevalent problems self-reported by professional mermaids. Indeed, $87.5 \%$ of the respondents reported ear issues. All of the respondents who reported ear issues mentioned at least one event of ear infection. A total of 17 ear infection events were reported (occurrence rate: 1 ear infection per 1,126 h of mermaiding). Among these ear infection events, 11 originated from pools (occurrence rate: 1 ear infection per 1,149 h of mermaiding), 8 from sea or aquariums containing salt

Table 2. Repartition of mermaiding activities

\begin{tabular}{llll}
\hline Type of setting & Per cent of time & Number of hours & Per cent of time (in-water) \\
\hline Mermaid schools & $35.6 \pm 35.6$ & 7042 & $37.2 \pm 37.1$ \\
Open water & $22.9 \pm 27.7$ & 4530 & $23.1 \pm 27.6$ \\
Private parties & $17.7 \pm 17.2$ & 3501 & $18.9 \pm 19.5$ \\
Aquariums & $10 \pm 26.3$ & 1978 & $10.1 \pm 26.3$ \\
Nightclubs & $3.1 \pm 7$ & 613 & $3.1 \pm 7$ \\
Hotels & $2.8 \pm 3.1$ & 554 & $2.9 \pm 3.2$ \\
Resorts & $2.7 \pm 3.7$ & 534 & $2.7 \pm 3.7$ \\
Water sports events & $1.2 \pm 3.5$ & 237 & $1.2 \pm 3.5$ \\
Movies/films & $0.5 \pm 1.4$ & 99 & $0.5 \pm 1.4$ \\
Casinos & $0.3 \pm 0.5$ & 59 & $0.3 \pm 0.5$ \\
Total (in-water) & 96.8 & 19,147 & 100 \\
Dry gigs & $3.2 \pm 5.9$ & 633 & \\
Total & 100 & 19,780 &
\end{tabular}


Table 3. Types of health issues related to mermaiding

\begin{tabular}{|c|c|c|c|c|}
\hline Type & $\begin{array}{l}\text { Reported } \\
\text { occurrence }\end{array}$ & $\begin{array}{l}\text { Degree } \\
\text { of severity }\end{array}$ & Type of water & Origin \\
\hline Ear issues & $87.5 \%$ & Major & Any water & Mermaiding \\
\hline Sea life encounters & $50 \%$ & Variable & Salt water (sea or aquariums) & Mermaiding \\
\hline Back pain & $50 \%$ & Minor & Unclear & Tail and fins \\
\hline Cold-related issues & $37.5 \%$ & Minor & Sea & Mermaiding \\
\hline Lower limbs issues & $37.5 \%$ & Minor & Any type of water & Tail and fins \\
\hline Eye issues & $25 \%$ & Minor & Pools & Water quality (chlorine) \\
\hline $\begin{array}{l}\text { Compromised } \\
\text { access to air }\end{array}$ & $25 \%$ & Major & Any type of water & $\begin{array}{l}\text { Lack of attention of supervisor } \\
\text { or safety diver }\end{array}$ \\
\hline Other infections & $12.5 \%$ & Major & Mostly pools & Water quality (waterborne illnesses) \\
\hline
\end{tabular}

water (occurrence rate: 1 ear infection per $813 \mathrm{~h}$ of mermaiding), and 3 happened in a context of mixed swimming (period of swimming taking place alternatively in sea and in pool, increasing the occurrence rates to 1 ear infection per $903 \mathrm{~h}$ of mermaiding, and 1 ear infection per $592 \mathrm{~h}$ of mermaiding, for pool and sea respectively). In addition to ear infection, $50 \%$ of the mermaids complained from chronic ear issues (57\% of the mermaids having reported ear issues), mostly eardrum problems and ear aches. Ear infection was sometimes reported to extend to the sinus, preventing free diving during several days. Given the fact that ear infections usually require antibiotherapy, these issues can be considered as major.

Problems related to encounters with sea life were reported by $50 \%$ of the respondents. While some of such encounters were minor (e.g., minor cuts from coral, reefs, or sharp oysters, or stepping on sea urchins), some encounters were more problematic, as they involved potentially dangerous animals. The first type of animals representing a potential threat was poisonous invertebrates, such as jellyfishes, with a few jellyfish stings reported by at least two different mermaids. The second type of dangerous animals was large predatory fishes, typically sharks of rays. Two mermaids reported unwanted contact with a shark due to miscalculated swimming trajectory of the mermaid, resulting in one case in a light burn after skin contact, and in the other case by having a great hammerhead shark pushed the mermaid through the water. While not leading to any injury, swimming in an aquarium with a ray had to be done under control of the animal keeper. In both cases, the presence of animal specialists with good knowledge of animal behaviour helped the mermaids to avoid further issues, allowing for a safe swimming. Such encounters obviously only occurred in salt water, but were reported both from open sea and aquariums.
Half of the respondents (50\%) reported some degree of back pain. However, the respondents mentioning back pain were explaining it by having to lift and carry around the tail and fins (which weight approximately $15 \mathrm{~kg}$ ). Furthermore, some of the respondents were mentioning having back issues before engaging into mermaiding. Therefore, the relation of back pain with mermaiding was not direct - linked to the fact of swimming with a mermaid tail - but indirect - related to the weight of the material itself, and having to carry it out-of-water. Whatever the origin, back pain were never reported as being a major issue by the respondents.

Issues resulting from exposition to cold water were reported by $37.5 \%$ of the respondents. The reported problems resulting from exposition to cold water were all affecting oto-rhino-laryngological systems, and included colds and influenza-like symptoms, enduring ear aches, or pain in upper respiratory pathways putatively leading to transient suppression of breathing reflex. Most of the issues related to cold water were related to sea water, and were minor.

Lower limbs issues were reported by $37.5 \%$ of the respondents. Similarly to back pain, lower limbs problems were systematically associated with the tail and fins, and included minor issues such as foot blisters from the tail, foot or calf cramps, and pulled muscles. All issues related to lower limbs were minor. Co-occurrence of back pain and lower limbs issues was only marginal (30\% of the respondents reporting lower limb issues also reported back pain, and only $25 \%$ of the respondents reporting back pain reported lower limb issues).

A fourth of the respondents (25\%) reported minor eye issues (red eyes) following long exposure to chlorine. These issues were related to the quality of the water rather than a direct consequence of mermaiding, and were minor.

More problematically, a fourth of the respondents (25\%) reported risk of suffocation following a compromised access 
to air. In all cases, the issues came while the safety diver missed the signal from the mermaid that she was needing air. While the situation got solved without injury, it points out the responsibility of co-divers in keeping professional mermaiding practitioners safe (A similar situation was reported to the author during preliminary investigations, when a mermaid performing in a water tank in a nightclub got her access to air compromised when the person supposed to supervise her was not paying attention to her air-request signals.) Despite their limited occurrence, these events could have had potentially dramatic consequences.

One mermaid reported multiple infections ranging from nasal infections (2 events in non-public pools) to skin infections (4 events in non-public pools, 5 events in lakes) and parasite infection (1 event in non-public pool). These issues are major, but being isolated, appear to be related to a problem of the quality of water rather than to mermaiding per se.

Finally, a few minor issues were reported such as bumping once against the bottom of a pool (the same event was described by a second mermaid while relating to a swimmer learning mermaiding), or minor cut from rocks. Such issues were rarely mentioned and are obviously of very minor consequences in terms of health.

\section{SELF-REPORTED QUALITATIVE COMMENTS}

In addition to health-related questions, the survey allowed the respondents to provide additional comments. Surprisingly, most respondents used this possibility extensively, sharing valuable insights about health and safety-related issues of mermaiding (Table 4). In general, the respondents were taking safety issues very seriously and reported being proactive with prevention (particularly concerning prevention of infections, blistering, hypothermia and fatigue). The respondents emphasised the importance of having a proper level of formation, i.e., free diving of scuba diving training and certification. Several respondents mentioned the key importance of having a safety diver trained in first aid when performing (in the context of mermaid schools, some respondents mentioned having a student/instructor ratio of 5 , and supervision was deemed important in swimming pool). The respondents were aware of the dangers inherent to diving in ocean, and mentioned the need of having the assistance of experienced ocean divers and/or animal behaviourists when diving in complex conditions (such as in wild areas, in areas with important tides, or in presence of potentially dangerous animals). The importance of the interaction between the mermaid and the clients was also noted, as the clients have to enforce appropriate safety conditions. Several respondents expressed concerns regarding mermaiding for small children. It was repeatedly mentioned that children willing to use a tail should first be able to swim perfectly without assistance in deep water. The respondents who
Table 4. Principal self-reported concerns and issues related to mermaiding safety

Optimising prevention
Importance of having free diving or scuba diving certification
Presence of safety divers trained in first aid
Supervision by lifeguards in swimming pools
Assistance of experienced ocean divers/animal behaviourists
when diving in ocean
Contracts dictating safety parameters for clients
Concerns regarding small children training
Concerns regarding the quality of commercial tails,
especially children tails
Concerns regarding shared pool facilities between
regular swimmer and mermaids

mentioned a minimal age considered that it was not safe for a child below 8 years old to start mermaiding. Related to that, several responded expressed concerns regarding the quality of commercial tails, especially those potentially sold to children. Finally, concerns were raised regarding the cohabitation of regular swimmers and mermaids in a same pool (with the suggestion of using clearly separated areas or times to avoid shocks given that mermaids are mostly underwater specialists and not surface swimmers).

\section{DISCUSSION}

As for any swimming style - or, for that matter, any physical activity - mermaiding and related forms of professional aquatic entertainment bear some risks. However, in the light of the present survey, the occurrence of problematic conditions appears limited. Interestingly, the profile of health issues experienced by professional mermaids is quite unique and specific, and clearly different from both professional swimmers and surfers - two populations which could have been a priori considered as template for mermaids.

An issue common to any observational study is to insure a satisfactory level of representativeness of the data gathered. While in the present case, the results suggest that the saturation level was reached, the lack of current literature on mermaiding made it difficult to evaluate what a proper sample size should be. Since mermaiding is still nascent form of swimming, it does not yet gather a number of practitioners comparable to those of other recreational aquatic activities. A reasonable comparison could be made with what is done in the field of monofin research. The average size of the samples of the 5 most recent papers available on PubMed on monofin swimming (search performed on PubMed using "monofin" as keyword, last consulted December 2, 2016) was of $7.6 \pm$ \pm 5.4 [8-12]. Therefore, the sample size of the present study was considered as an acceptable target. Given the overall 
number of hours of practice taken into account in this study, the results presented here are to be considered as a robust base. Although the number of cumulative hours results from estimation rather than from an exact count, what matters here is that it provides a reasonably fair order of magnitude. Although the population of professional mermaids sampled in the present study might be limited, the variety of the settings and experience results in a situation where almost all - or at the very least a lot of - potentially dangerous situations have been experienced at a point or another.

The main health problems reported by professional mermaids were ear issues. This might not be surprising as ear issues are one of the triad of symptoms of waterborne illnesses - ear infections, skin problems, digestive problems including diarrhoea and vomiting [13]. However, ear problems occurred for mermaids without the other symptoms. A few elements could contribute to explain this phenomenon. First, in contrast to swimmers or divers, professional mermaids are not using swimming cap, and seldom use ear plugs (only 2 respondents reported using ear plugs in this study). Second, in contrast to surfers who are also massively exposed to sea water and present high incidence of gastro-intestinal symptoms such as diarrhoea or vomiting [6], mermaids are usually experienced free divers and they are less likely to swallow water (in contrast to a surfer, a mermaid does know when she is underwater and is less likely to be "taken by surprise" by a wave). In the present study, one respondent reported a large range of infectious issues, covering the full spectrum of waterborne illness symptoms. This clearly pointed to a suspected issue of water quality. All the infectious events were related to non-public pools (in this case hotel pools), for which controls of water quality might be lacking. Future studies might aim at documenting which factors or specific behaviour (such as the use of personal protective equipment) could alter - increase or ideally decrease - the odds of acquiring waterborne illnesses for mermaiding practitioners.

The profile of health issues experienced by professional swimmers is mainly characterised by joint problems. Injuries related to swimming usually involve upper limbs more than lower limbs, and are principally arising from overuse of one or more of the four competitive strokes practiced with errors $[7,14]$. Since the emphasis of mermaiding is not on speed but rather on fluidity of the movements, and that propulsive power is provided by the specific monofin entrapping the legs more than by upper members' strokes, mermaiding is - at least in regards to upper members - a less injury-inducing activity. Similarly, lower limbs problems associated with swimming are usually the result of repetitive use of specific kicks, either breaststroke kick in swimmers or "egg beater" kick in water polo players and synchronised swimmers [7], something which is obviously different for mermaids. Back pain is also a common feature of swimmers [7]. Despite being regularly mentioned by mermaids, the occurrence of these issues is not comparable with what conventional swimmer experience. First, both back pain and lower limbs problems were systematically described as minor - more inconveniencies than bona fide issues. Second, the case of mermaids however, both back pain and lower limbs issues were clearly related to the tail (either its weight or the prolonged contact of the artificial tail on the skin) rather than a direct consequence of mermaiding itself. From a clinical point of view, these two types of health problem in mermaids (back pain and lower limbs issues) not only have a different magnitude than the problems experienced by conventional swimmers, but they also have a completely different aetiology. Indeed, while these health issues have an intrinsic origin (related to swimming technique) for conventional swimmers and other aquatic athletes, they have an extrinsic origin (the material used to swim, and its out-of-water transportation) for mermaids. Although back pain is likely related to the material rather than the mermaiding practice itself, it should nonetheless be considered when developing a global health response for mermaiding practitioners. However, as the mermaid tail and fins market will grow with the increase of mermaiding popularity, new products are likely to emerge that will alleviate at least partially these issues.

Beside ear problems which appear to be a constant of mermaiding, the other potential health risks related to mermaiding vary greatly depending on the type of practice, i.e., recreational vs. professional. While, from the results of this study, recreational mermaiding seems to present mostly minor risks which are shared with other users of swimming pool facilities, professional mermaids face, due to the variety of the settings in which they evolve, more problematic situations. Beside issues related to questionable water quality in some non-public venues, most of the potentially problematic situations happen in sea and salt water. The two main issues related to sea swimming were the effects of sustained exposure to cold water, and the problem of encounters with sea life, particularly poisonous animals or large predators. Of note, these threats are typical of professional mermaiding activities, and are unlikely to be encountered in purely recreational mermaiding. Jellyfish stings are a relatively common for open sea swimmers, but in the case of professional mermaiding, the situation is worsened by the fact that mermaids have limited visibility as they don't wear mask underwater, and by the fact that mermaids usually have a relatively large amount of skin exposed - hence increasing potential surface of contact. In any case, while no major incident was reported in this study, the potential dangers related to sea life should not be neglected, and should be taken into consideration when attempting to perform with wild sea creatures. Finally, some 
of the potentially most dangerous situations are not under the direct control of the mermaid. This is notably the case of risks of suffocation when the mermaid is dependent of another person to get access to air.

It is important to remind here that, all mermaids who participated in the present study were experienced professionals, all of them being certified divers. Furthermore, they reported regular presence of security divers or other underwater assistants able to provide help if needed. As mermaiding becomes more popular, new aquatic entertainers might be performing without having the proper diving training - something which was expressed as a concern by several of the respondents of this study. In such situation, more accidents might occur. While this study represents a first step in our understanding of the problems mermaiding practitioners might have to face, more research is needed to explore further the health issues which might be related to mermaiding and the best way to avoid them.

\section{CONCLUSIONS}

The results presented here are an essential step to identify potential risks of mermaiding, and will help us build safer conditions for mermaiding activities. More importantly, they will also help us to develop adapted responses from health specialists to answer the present and future needs of this unique yet growing population of aquatic performers and athletes. One of the main conclusions of this study is that it emphases the central importance of education of both mermaids and safety divers to optimise prevention and decrease the risks of major injuries or accidents.

Since mermaiding is by definition an aquatic activity, all the health issues raised by mermaids can be found in the practice of other in-water activities. However, the practice of mermaiding increases some risks, thus leading to a specific profile when it comes to potential impact on health. Globally, four main factors can impact the occurrence of health issues for mermaids: first, mermaiding itself, which enhances some risks existing for other types of aquatic athlete (specifically: ear issues, marine fauna-related threats, and sustained exposure to cold water); second, the material used to swim (the tail), which can potentially trigger minor back pain due to its weight and, in some cases, moderate lower limbs fatigue; third, water quality which can affect eyes and be responsible for the exposure to waterborne disease vectors; and finally, supervision by professionals either experienced mermaiding teacher or security diver. As mermaiding is shifting from a professional to a recreational practice, and as more and more people are engaging this activity without a full underwater athlete training, these four factors will have to be considered when designing safe conditions for mermaiding to be practiced, and when devising appropriate training for health care professionals which might have to assist mermaids.

\section{ACKNOWLEDGEMENTS}

The author is extremely grateful to the professional mermaids who agreed to participate to this study, for their generosity in sharing their experience and insights.

\section{REFERENCES}

1. Guitton MJ. From fantasy, to virtual spaces, to reality, and back: Structuring the merfolk community. In: Guitton MJ ed. Fan Phenomena: Mermaids. Intellect, Bristol, 2016, pp : 64-73.

2. Fraser $\mathrm{H}$. The journey of a mermaid: Turning fantasy into reality. In: Guitton MJ ed. Fan Phenomena: Mermaids. Intellect, Bristol, 2016, pp : 22-27.

3. Guitton MJ. Swimming with mermaids: Communication and social density in the Second Life merfolk community. Computers in Human Behavior. 2015; 48: 226-235, doi: 10.1016/j.chb.2015.02.004.

4. Rivers C. Mermaid blogging. In: Guitton MJ ed. Fan Phenomena: Mermaids. Intellect, Bristol, 2016, pp : 74-77.

5. Chartier Hénault M. A mermaid school: Becoming a mermaid instructor. In: Guitton MJ ed. Fan Phenomena: Mermaids. Intellect, Bristol, 2016, pp : 48-51.

6. Harding AK, Stone DL, Cardenas A, et al. Risk behaviors and self-reported illnesses among Pacific Northwest surfers. J Water Health. 2015; 13(1): 230-242, doi: 10.2166/wh.2014.231, indexed in Pubmed: 25719482.

7. Nichols AW. Medical Care of the Aquatics Athlete. Curr Sports Med Rep. 2015; 14(5): 389-396, doi: 10.1249/JSR.0000000000000194, indexed in Pubmed: 26359841.

8. Boitel G, Vercruyssen F, Alberty M, et al. Kick frequency affects the energy cost of aquatic locomotion in elite monofin swimmers. Eur J Appl Physiol. 2010; 109(6): 1087-1093, doi: 10.1007/s00421010-1450-6, indexed in Pubmed: 20369367.

9. Vercruyssen F, Boitel G, Alberty M, et al. Influence of kick frequency on metabolic efficiency and performance at a severe intensity in international monofin-swimmers. J Sports Sci. 2012; 30(10): 1055-1061, doi: 10.1080/02640414.2012.690072, indexed in Pubmed: 22616596.

10. Oshita K, Ross M, Koizumi K, et al. Gender difference of aerobic contribution to surface performances in finswimming: analysis using the critical velocity method. Asian J Sports Med. 2013; 4(4): 256-262, indexed in Pubmed: 24800000.

11. Paterakis KN, Brotis AG, Dardiotis E, et al. Acute Schmorl's Node during Strenuous Monofin Swimming: A Case Report and Review of the Literature. Global Spine J. 2012; 2(3): 159-168, doi: 10.1055/s-0032-1307262, indexed in Pubmed: 24353963.

12. Rejman M. Analysis of relationships between the level of errors in leg and monofin movement and stroke parameters in monofin swimming. J Sports Sci Med. 2013; 12(1): 171-181, indexed in Pubmed: 24149742.

13. De Man H, Mughini Gras L, Schimmer B, et al. Gastrointestinal, influenza-like illness and dermatological complaints following exposure to floodwater: a cross-sectional survey in The Netherlands. Epidemiol Infect. 2016; 144(7): 1445-1454, doi: 10.1017/ S0950268815002654, indexed in Pubmed: 26554647.

14. Jones JH. Swimming overuse injuries. Phys Med Rehabil Clin N Am. 1999; 10: 77-94 vi. 